\title{
The Analysis and Prediction of Water Supply and Demand for Beijing in future
}

\author{
Jing Han \\ School of North China Electric Power University, Baoding 071003, China; \\ 1933723786@qq.com
}

\begin{abstract}
Keywords: Water Shortage Gray Correlation Analysis Sequential Combination Forecasting ,Grey Forecasting Polynomial Fitting
\end{abstract}

\begin{abstract}
The paper chooses data of the water resource supply and demand in Beijing in previous years, adopting gray correlation analysis method to analyze three main factors of water. Sequential Combination Forecasting ,Grey Forecasting and polynomial fitting method are respectively used to predict changes of three main factors in the future.Finally, according to the forecast data, the supply and demand situations of water resource and influence of the situations are analyzed.
\end{abstract}

\section{Introduction}

We choose Beijing for analysis which is a serious shortage of water resources in the city.Per capita has 366.8 cubic meters of water per year, accounting for only $13.8 \%$ of the national average, in the capital of the world's 120 countries after a hundred. With the development of economy and the improvement of living standard, the demand of water resources is increasing. At the same time, there are serious groundwater overdraft, serious water pollution, waste and other phenomena, the contradiction between supply and demand of water resources is even more acute. Next we analyze and explain why and how water is scarce in Beijing. Besides, we predict the supply and demand of water resource in Beijing in future.

\section{Reason of water shortage}

\subsection{Analysis of Supply and Demand of Water Resources}

A regional water supply includes utilizable precipitation, renewable water, water diversion project, groundwater exploitation, entry water and other five aspects. They are defined as :

Utilizable precipitation : $X_{1}$

Renewable water : $X_{2}$

Water diversion project : $X_{3}$

Inflows of rivers : $X_{4}$

A regional water demand includes four parts: domestic water, industrial water, agricultural water and environmental water. They are defined as :

Domestic water : $X_{5}$

Industrial water : $X_{6}$

Environmental water : $X_{7}$

Agricultural water : $X_{8}$

\subsection{The gray correlation analysis method}

The gray correlation analysis method is a multivariate statistical analysis method. It is based on the sample data of each factor to describe the relationship between the factors by using the gray correlation degree.

The steps of Grey Relational Analysis are as follows:

1) Determine the evaluation objects (comparative series) and the reference sequences.Assume the number of the evaluation objects is $m$; the number of the evaluation indexes is $n$; the reference sequence is 
$z_{0}=\left\{z_{0}(k) \mid k=1,2, \ldots, n\right\}$

The evaluation objects are $z_{i}=\left\{z_{i}(k) \mid k=1,2, \ldots, n\right\}, i=1,2, \ldots, m$.

2) Determine weight of each index value $w=\left[w_{1}, \ldots, w_{n}\right]$.

3) Calculate Grey correlation coefficient:

The correlation coefficient of the evaluation objects to the $k_{\text {th }}$ index of the reference sequence is $\xi_{i}(k)=\frac{\min _{s} \min _{t}\left|z_{0}(t)-z_{s}(t)\right|+\rho \max _{s} \max _{t}\left|z_{0}(t)-z_{s}(t)\right|}{z_{0}(k)-z_{i}(k)\left|+\rho \max _{s} \max _{t}\right| z_{0}(t)-z_{s}(t) \mid}$.

resolution coefficient is $\rho \in[0,1]$.

Generally, resolution coefficient and resolution ratio are positive correlation.

4) Calculate grey weighted relation. The calculating formula of grey weighted relation is:

$$
r_{i}=\sum_{k=1}^{n} W_{k} \xi_{i}(k) \text {. }
$$

Grey weighted relation of the $k_{\text {th }}$ evaluation object for the reference sequence is $r_{i}$.

5) Evaluate and analyze. According to the value of the grey weighted relation, the order of the relation of the evaluation objects can be established. The more relation, the greater evaluate.

\subsection{Simulation}

1) The annual water shortage in this region from 2001 to 2014 is considered as $z_{0}$.

Table1: annual Water Shortage in Beijing

\begin{tabular}{cccccccc}
\hline Year & 2001 & 2002 & 2003 & 2004 & 2005 & 2006 & 2007 \\
\hline $\begin{array}{c}\text { Water } \\
\text { Shortage } \\
\mathbf{1 0} \wedge \mathbf{8}^{*} \mathbf{m} \wedge \mathbf{3}\end{array}$ & 14.59 & 15.9 & 11.12 & 4.88 & 1.61 & 1.55 & 0 \\
\hline Year & 2008 & 2009 & 2010 & 2011 & 2012 & 2013 & 2014 \\
\hline $\begin{array}{c}\text { Water } \\
\text { Shortage } \\
\mathbf{1 0} \wedge \mathbf{8}^{*} \mathbf{m} \wedge \mathbf{3}\end{array}$ & 0 & 0 & 0 & 0 & 0 & 0 & 1.61 \\
\hline
\end{tabular}

2) Supply and demand of water are considered evaluation objects $Z_{i}$, including amount of utilizable precipitation, renewable water, water-transfer, agricultural water, industrial water, living water, environmental water. Years are defined 14 evaluation indexes. Resolution coefficient defined $\rho$ is equal to 0.5. Assume that the weights are equal to each index, that is, weight matrix as $w=[1 / 14, \ldots, 1 / 14]$.Due to differences of dimensions of evaluation objects, data is needed be normalized. According to the above mentioned the steps of Grey Relational Analysis, the relation between the reference sequence and the evaluation objects can be obtained as following chart:

Table2: the Relation between the Evaluation Objects and the Reference Sequences

\begin{tabular}{lcccccccc}
\hline $\begin{array}{l}\text { Evaluation } \\
\text { Objects }\end{array}$ & $X_{1}$ & $X_{2}$ & $X_{3}$ & $X_{4}$ & $X_{5}$ & $X_{6}$ & $X_{7}$ & $X_{8}$ \\
\hline Relation & 0.5385 & 0.7534 & 0.7854 & 0.8055 & 0.7126 & 0.8047 & 0.650 & 0.7985
\end{tabular}

3) The conclusion from relation matrix: $r_{4}>r_{6}>r_{7}>r_{3}>r_{2}>r_{8}>r_{5}>r_{1}$. The relation of agricultural water, industrial water respectively and water shortage is more than $80 \%$.The three factors mainly result in water shortage in this region. 


\section{Prediction of water resource in the future}

We choose three the highest relation from above eight factors, respectively inflows of rivers,industrial water, environmental water, to predict their changes in next 5 years.

\subsection{Sequential Combination Forecasting Model}

If a region in the near future has no much changes of water conservancy project, the significant features of the change of the annual inflows of rivers in the next short term will be in the mean fluctuation. The inflows of rivers forecasting model adopts sequential combination forecasting based on mean generation function based on the mean generation function, which includes the mean function, the periodic extension matrix and the Schmidt quadrature method. Sequential Combination Forecasting Model is used to predict the inflows of rivers, and the results are as follows:

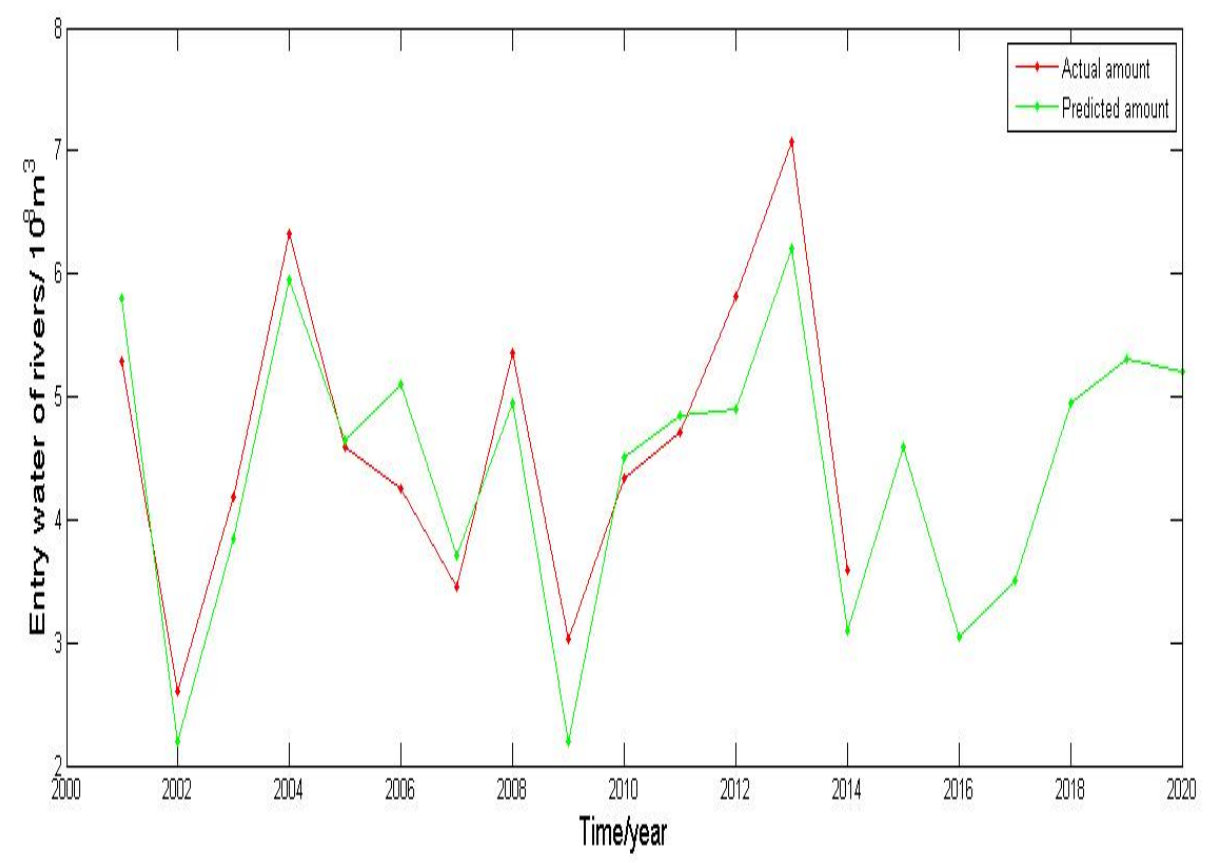

\subsection{Grey Forecasting Model}

Figure 1 :Forecasting of Inflows of Rivers

Grey system theory regards all random variables as grey numbers, and it is not to find the statistical law or the statistical distribution, but to use the data processing method to excavate the law between the data.

1) Gray prediction method is used to predict the industrial water consumption, and the results are as follows:

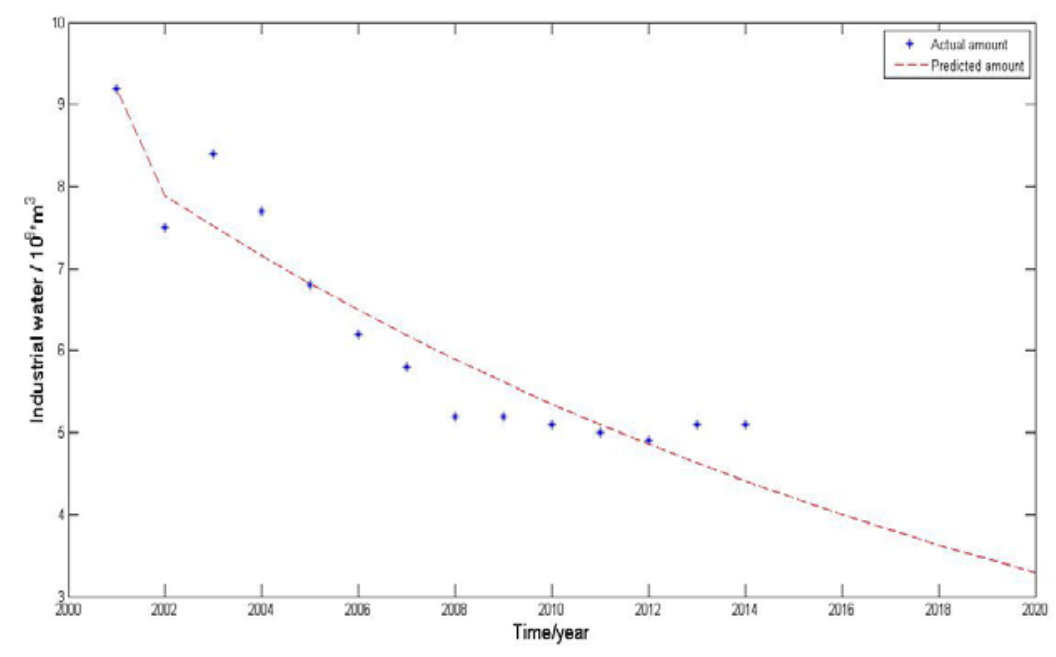

Figure 2 :Forecasting of Industrial Water 
2) Gray prediction method is used to predict the environmental water, and the results are as follows:

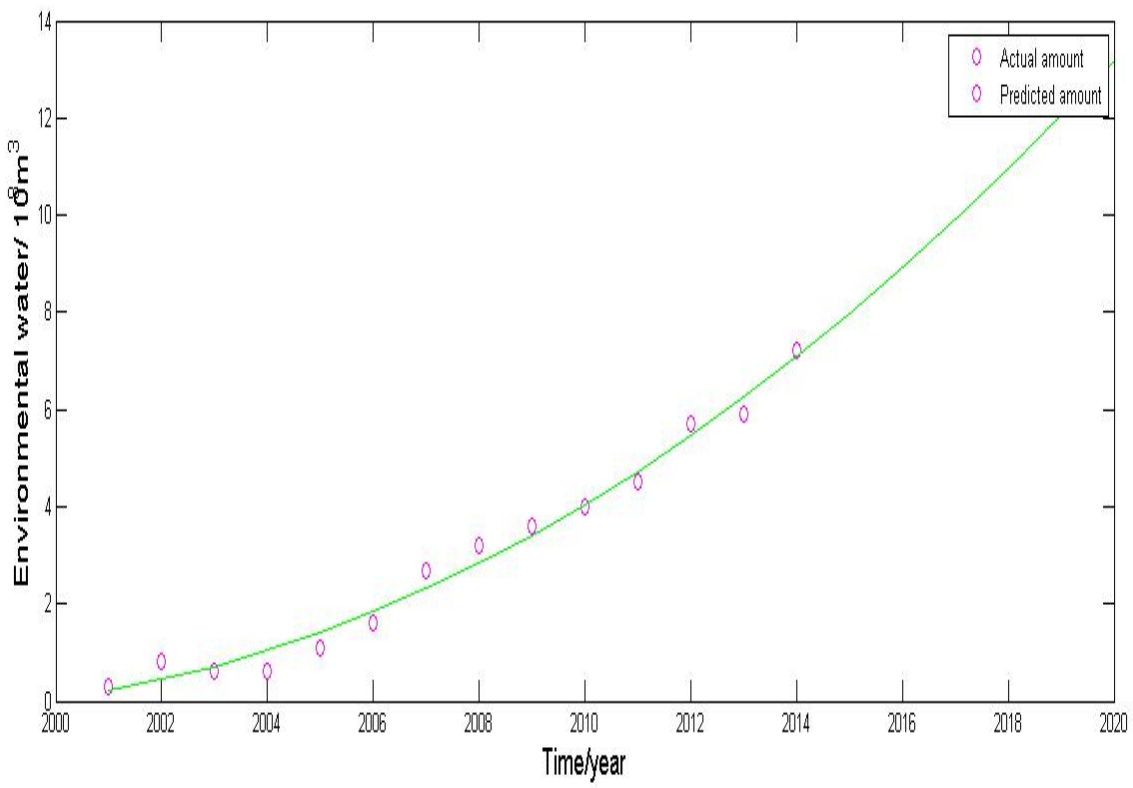

Figure 3:Forecasting of Environmental Water

\section{Summary}

In the next 5 years, inflows of rivers of Beijing city will be still in the wave dynamic potential and not drastic changes. Industrial water will decrease while environmental water will increase and the upward trend is large year by year. There will be no good solution to resolve to water shortage, and the situations of supply and demand of water resource will be not still optimistic in Beijing in the future.

\section{References}

[1] Shoukui Si, Xijing Sun. Mathematical Modeling[M]. National Defend Industry Press , September 2014.

[2]. Beijing water resources bulletin.

[3]. Beijing statistical yearbook 2015.

[4].research and application of rainfall forecasting model. http : // wenku. baidu. Com /view /88 f27 $58471 \mathrm{f}$ e9 10 ef 12 d f 8 a 4 . html 